\section{Generics: an enigma?}

\author{
Phil Wiffen
}

It has been a couple of months when the topic of generics has popped up repeatedly. It started with several papers submitted to the journal, including one published in this issue. The issue was further highlighted by a paper and accompanying editorial in a recent Annals of Internal Medicine. The editorial by Sherer ${ }^{1}$ quotes data showing that generic antiretroviral drugs have helped to decrease mortality by $24 \%$ since 2005, thereby leading to a decrease in new cases of HIV infections of $20 \%$ since 2001. On the other hand, Sherer states that 10 generic antiretrovirals available in the USA are used infrequently because of greater toxicity and inferior efficacy. The articles are stimulated by the availability of generic efavirenz due this year. This gets to the heart of the dilemma. The linked article by Walensky et $a l^{2}$ is a cost-effectiveness analysis looking forward. The authors compare three scenarios for antiretroviral therapy (ART); no ART for comparison, a three-pill version of generic-based ART consisting of generic efavirenz, generic lamivudine and branded tenovir, finally a one-pill efavirenzemtricitabine-tenovir branded combination.

The analyses are complex, but the authors suggest that by changing to the three-pill generic from the one pill could save around US\$6100 per patient per year, with accumulated savings for the USA

Correspondence to Professor Phil Wiffen,

Pain Research Unit, Churchill Hospital, Old Road, Oxford OX3 7LE, UK; phil.wiffen@ndcn.ox.ac.uk estimated at US\$920 million-not an insignificant sum-and an opportunity to fund other treatments. This is not likely to be a free ride, however, as there are uncertainties over the clinical significance of the change from emtricitabine to lamivudine. The estimated reduction in efficacy could lead to an earlier death by around 4 months, assuming that patients take the three-pill option compared with the one pill.

Another paper assessing bioequivalence of antiepilepsy drugs (AED) by Krauss et $\mathrm{al}^{3}$ suggests that 'switches between generic AED products may cause greater changes in plasma drug concentrations than generic substitutions of reference products'. This is worrying for patients who often do not get the same generic product with each repeat prescription. To potentially lose control of seizures is no small matter.

What we do not know is whether there will be other unintended consequences of generic switching. A change here in the UK was from a combined paracetamol $500 \mathrm{mg} /$ codeine $60 \mathrm{mg}$ tablet to providing the components separately as a means of saving on budgets. While many people managed on this, a significant number of patients became confused and either suffered in pain or accidentally overdosed on the codeine component leading to hospitalisation to sort the issue out, but of course, this cost did not show up on the medicines budget!

Having worked in a developing country, and also worked with WHO's essential medicines committee, I see the huge benefits of generic medicines. In fact, many people in developing countries are healthier and alive because of them. Yet there is a nagging doubt that we need to be careful in automatically assuming that a generic, because it is licenced, is as good as the original product, particularly in complex medicine. What are the rules? Are there any? This is an issue for primary care as well as hospital pharmacy, but we cannot ignore the issue, as in many areas hospital pharmacy gives a lead.

I am therefore keen to stimulate a debate. I am planning that issue 4 of the EJHP which is the August edition will have a theme on generic medicines with a number of different viewpoints. It would be sensible to gain an overview of views and details of policy decisions from across Europe. Please send those in and I will aim to publish them in a suitable format.

Competing interests None.

Provenance and peer review Commissioned; internally peer reviewed.

To cite Wiffen P. Eur J Hosp Pharm 2013;20:67.

Eur J Hosp Pharm 2013;20:67.

doi:10.1136/ejhpharm-2013-000286

\section{REFERENCES}

1 Sherer R. Generic antiretrovirals and the uncertain future of HIV care in the United States. Ann Intern Med 2013;158:133-4.

2 Walensky RP, Sax PE, Nakamura YM, et al. Economic savings versus health losses: the cost-effectiveness of generic antiretroviral therapy in the United States. Ann Intern Med 2013;158:84-92.

3 Krauss GL, Caffo B, Chang YT, et al. Assessing bioequivalence of generic antiepilepsy drugs. Ann Neurol 2011;70:221-8. 